This is the final peer-reviewed accepted manuscript of:

Ricchi, T., Alagna, V., Villani, G., Tomei, F., Toscano, A., Baroni, G., " Sensitivity of the agro-hydrological model CRITERIA-1D to the Leaf Area Index parameter," 2020 IEEE International Workshop on Metrology for Agriculture and Forestry (MetroAgriFor), Trento, 2020, pp. 247-251, doi: 10.1109/MetroAgriFor50201.2020.9277614.

The final published version is available online at:

https://doi.org/10.1109/MetroAgriFor50201.2020.9277614

Rights / License:

The terms and conditions for the reuse of this version of the manuscript are specified in the publishing policy. For all terms of use and more information see the publisher's website. 


\section{Sensitivity of the agro-hydrological model CRITERIA-1D to the Leaf Area Index parameter}

\author{
Tamara Ricchi \\ Department of Agricultural and Food \\ Sciences (DISTAL) \\ University of Bologna \\ Bologna, Italy \\ tamara.ricchi@unibo.it
}

\author{
Fausto Tomei \\ Arpae, SIMC \\ Bologna, Italy \\ ftomei@arpae.it
}

\author{
Vincenzo Alagna \\ Department of Agricultural and Food \\ Sciences (DISTAL) \\ University of Bologna \\ Bologna, Italy \\ v.alagna@unibo.it \\ Attilio Toscano \\ Department of Agricultural and Food \\ Sciences (DISTAL) \\ University of Bologna \\ Bologna, Italy \\ attilio.toscano@unibo.it
}

\author{
Giulia VIllani \\ Arpae, SIMC \\ Bologna, Italy \\ gvillani@arpae.it
}

\author{
Gabriele Baroni \\ Department of Agricultural and Food \\ Sciences (DISTAL) \\ University of Bologna \\ Bologna, Italy \\ g.baroni@unibo.it
}

\begin{abstract}
Water availability is strongly variable in space and time, also due to the climate change. Agriculture is a sector specially affected by the water scarcity problem considering that is one of the main users. Irrigation scheduling simulation models play an important role in this context by estimating plant water requirements and supporting best water management practices. Representative model parameters and input data are however fundamental to achieve good model performances. The objective of this work was to assess the sensitivity of the agrohydrological model CRITERIA-1D to the leaf area index (LAI) parameter, commonly used to characterize the plant status and to represent its developing stages. The model has been set up using, on the one hand, literature LAIMAX and LAIMIN values and, on the other hand, ground measured values, obtained by means of a ceptometer. Results show significant differences between the irrigation water requirements estimated between the two scenarios. For this reason, the study underlines the need to adopt accurate crop parameters and to integrate real-time crop measurements for the estimation of the irrigation water requirement. Smaller differences are quantified, however, when looking at the deep percolation estimated by the model highlighting the importance of considering multiple outputs for a comprehensive assessment of the model.
\end{abstract}

Keywords-Soil water balance models, crop, pear, water need estimation, LAI, ceptometer

\section{INTRODUCTION}

Nowadays the agriculture sector uses about two third of worldwide freshwater availability. As the resource is increasingly deficient, one of most appropriate ways to reduce water use in agriculture is by supplying the exact amount of irrigation to crops when it is required, so that water use efficiency can be maximized [1].

To address these issues and support agricultural water management, agro-hydrological models of different complexity have been developed to simulate mass and energy exchange processes in the soil-plant-atmosphere system [2]. These models have been used in several conditions showing to provide support for integrating best management practices and to achieve a sustainable use of the water resources [3][5].

These models, however, are very sensitive to many input and parameters [6] and their applicability at large scales can be limited by the availability of input data and parameters and their accuracy [7]. For these reasons, several studies aimed to improve model performances by integrating new observations [8], calibrating the model in comparison to independent data and based on different objective functions [9] or by data assimilation techniques [10].

In principle, ground-based measurements can be preferred as they are the most accurate. These measurements are however time-consuming and sometimes expensive. For this reason, applicability of this approach at large scale is often limited. Significant improvements in irrigation water assessment at the farm level can be obtained by assessing crop water needs through an optimal combination of crop satellite images with a crop growth model [11]. Nowadays many satellite products are in fact free available in almost real time (within a few hours from the acquisition time), and they can be quickly integrated for improving model prediction [12]. In this context, it becomes very important to assess which input and parameters might be more relevant for improving the performance of the model and to prioritize data collection and model integration [8], [13], [14].

In this study the agro-hydrological model CRITERIA-1D (github.com/ARPA-SIMC/CRITERIA1D) is used with the final aim to understand the influence of the parameter Leaf Area Index (LAI ) on the estimation of crop water requirements. LAI is one of the most relevant vegetation parameters and it is geometrically defined as the total onesided area of photosynthetic tissue per unit ground surface area [15]. To assess the sensitivity of the model to this parameter, CRITERIA-1D model was set-up to mimic the agro-environmental conditions of an orchards experimental site. Two different scenarios are then defined: in the first scenario, literature $\mathrm{LAI}_{\mathrm{MIN}}$ and $\mathrm{LAI}_{\mathrm{MAX}}$ values are used; in the second scenario the model is implemented with measured values collected at the experimental site with the AccuPAR LP80 ceptometer. This analysis was conducted in the framework of the SWAMP project (http://swampproject.org/).

\section{CRITERIA 1-D SIMULATION MODEL}

CRITERIA-1D is an open-source model developed by the environmental regional agency ARPAE Emilia-Romagna. The code is written in $\mathrm{C}++$ with Qt libraries available under the LGPL license and it can be compiled on several platforms. 


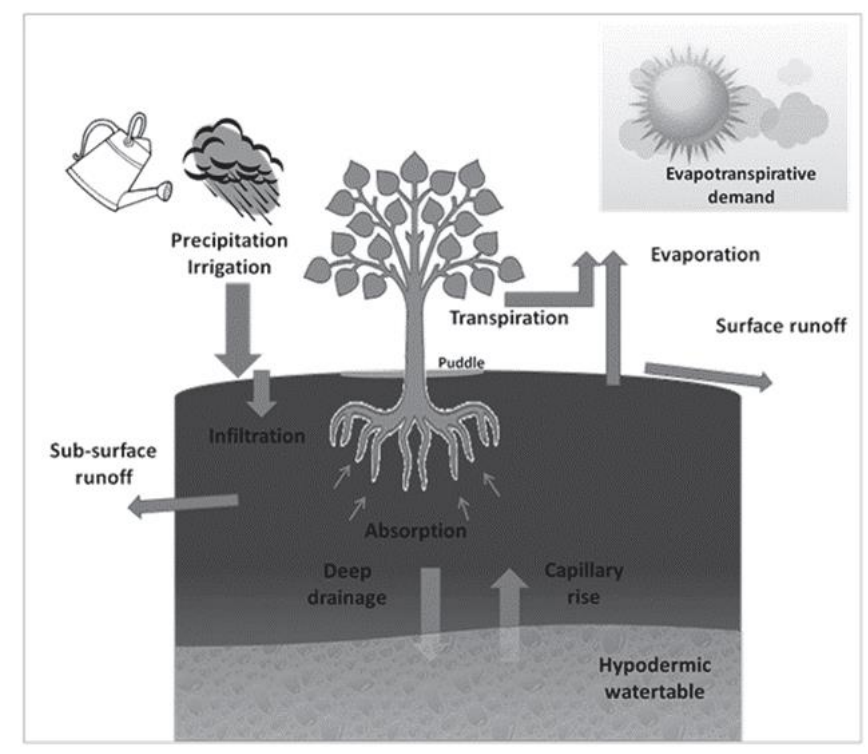

Fig. 1. Soil water balance representing the water fluxes simulated by CRITERIA-1D [3].

CRITERIA-1D simulates all the main hydrological processes of the soil-plant system based on the approach described by Driessen [16] and Driessen and Konijn [17]. A conceptual scheme of the simulated processes is represented in Fig. 1. The model assumes a multilayered soil (each layer of $2 \mathrm{~cm}$ ) and computes daily actual evaporation and transpiration, water fluxes between layers, deep drainage, surface and subsurface runoff and capillary rise. The model requires as input soil and crop parameters and daily meteorological data, namely minimum and maximum temperatures, total precipitation and, if available, potential evapotranspiration and shallow water table depth [3]. The model runs at a daily time scale and it simplifies the spatial variability by assuming that the cropped field is represented by average conditions and parameters.

Crop developments are explicitly accounted by the phenological stages of the plants. Specifically, the factor that determines the growth is the growing degree-days GDD. This is a measure of heat accumulation frequently used to describe the timing of biological processes [18]. GDD is computed using the daily maximum and minimum temperature $T_{\max }$ and $T_{\min }\left[{ }^{\circ} \mathrm{C}\right]$, and a base temperature $\left[{ }^{\circ} \mathrm{C}\right]$ that is defined as the minimum temperature depending on the crop that must be achieved to start the development of roots and leaves. CRITERIA-1D uses the parameter LAI to describe the leaf system development. LAI development is assumed to consist in 4 stages: (1) exponential growth of LAI; (2) linear growth of LAI; (3) decreasing growth rate of LAI; (4) decrease of LAI. For the first three phases, the equation that describes the LAI growth is:

$$
L A I=\frac{L A I_{M A X}-L A I_{M I N}}{1+e^{\left(a_{L A I}+b_{L A I} * \text { SumDegreeDay }\right)}}+L A I_{M I N}
$$

where $\mathrm{LAI}_{\mathrm{MIN}}, \mathrm{LAI}_{\mathrm{MAX}}$ are the maximum and minimum value for the crop, respectively; $a$ and $b$ are two parameters defined for each crop. Further details about the model can be found in the "CRITERIA technical manual" [19].

\section{STUDY AREA AND MODELLING SET-UP}

\section{A. Case study area}

The study area selected for this work is the San MicheleFosdondo irrigation district (Fig. 2) managed by the Consorzio di Bonifica dell'Emilia Centrale (CBEC), one of the eight reclamation consortia of the Emilia Romagna Region, Northern Italy. The area is characterized by an average annual temperature of $13.9^{\circ} \mathrm{C}$ and an average annual rainfall of $752 \mathrm{~mm}$. The pilot district has a total area of 892 ha of which 320 ha are irrigated.

For this study, the analysis has been performed at a pear orchard (Pyruscommunis L.) of about 1.2 ha, equipped with a drip irrigation system (Fig. 2). The field has been selected because of the importance of this crop in the selected area. The WGS coordinates of the field are 44.791091N, $10.736216 \mathrm{E}$. The area is characterized by warm summer with relatively low precipitations that are not able to satisfy the plant water requirements. For this reason, irrigations are commonly exploited throughout the growing season (AprilSeptember).

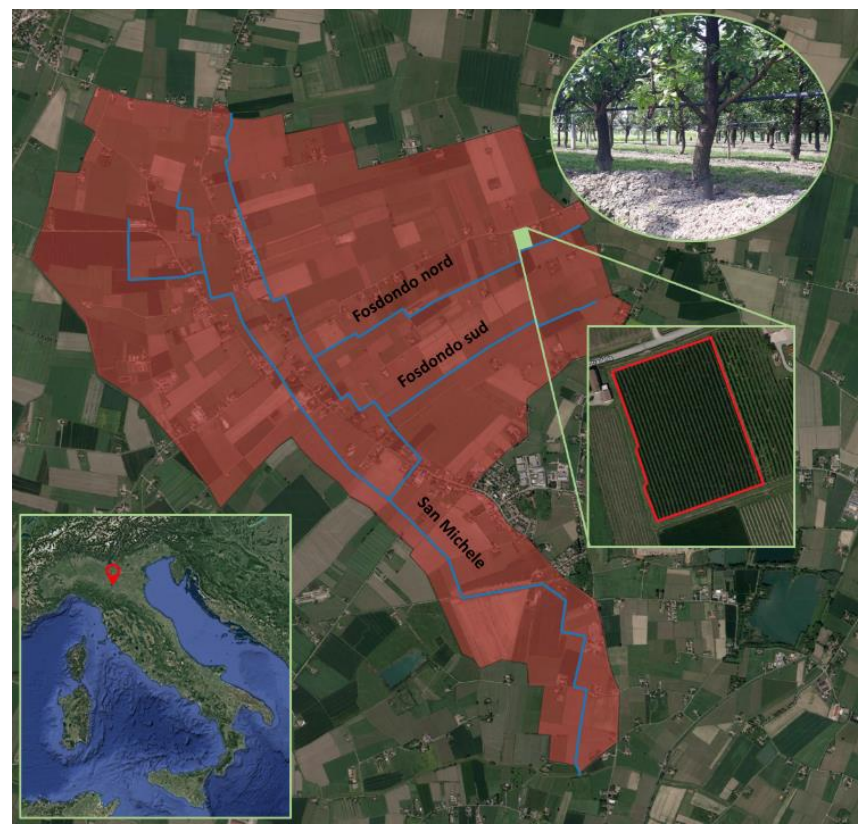

Fig. 2. San Michele Fosdondo irrigation district and the pear orchard experimental site.

\section{B. Model settings: data, parameters, and scenarios}

The CRITERIA-1D model has been implemented based on data and parameters collected at the experimental site as explained below in more detail.

a) Meteorological data: atmospheric precipitation, maximum and minimum temperature are derived from the database ERG5 from ARPAE. Meteo data are provided hourly and daily on a grid of $5 \mathrm{~km}$ side, interpolating measured data from regional meteorological stations (https://dati.arpae.it/dataset/erg5-interpolazione-su-grigliadi-dati-meteo). Specifically, data from the cell 01015 - S. Michele (WGS coordinates: 44.7675N, 10.7097775E) has been selected.

b) Water table data: groundwater levels are very important for the specific case study because the pear orchard is located in an area influenced by a shallow water table. Data have been provided from the monitoring network of the 
shallow water table of Emilia-Romagna region (http://faldanet.consorziocer.it/Faldanet/retefalda/index), the measuring point is 06RE. Measured data are gap-filled by means of an empirical algorithm [20] in order to obtain a continuous daily series [3].

c) Soil data: soil data are provided by the Geological, seismic and soil survey of Emilia Romagna regional database. For the selected area, the soil is SMB1 (Sant'Omobono 1), a typical silty loam soil of the region plain area.

d) Crop parameters: CRITERIA-1D needs several crop parameters including crop type, thermal thresholds, degree days depending on the plant development phase, roots depth and shape, crop coefficients, stress tolerance, $a$ and $b$ parameters. Concerning LAI, the model calculates values using default $\mathrm{LAI}_{\mathrm{MIN}}$ and $\mathrm{LAI}_{\mathrm{MAX}}$ model parameters.

Two scenarios are compared. The first reference scenario (hereafter called $S_{r e f}$ ) uses LAI values from literature. In the second scenarios, the LAI values directly measured at the experimental sites are integrated $\left(\mathrm{S}_{L A I}\right)$. Thus, the input parameters were the same as the reference one, except for $\mathrm{LAI}_{\mathrm{MIN}}$ e $\mathrm{LAI}_{\mathrm{MAX}}$ values.

LAI measurements (to replace the minimum and the maximum ones) were conducted with the optical instrument AccuPAR LP80 ceptometer (https://www.metergroup.com/environment/products/accupa r-lp-80-leaf-area-index/). During the summer 2019, four sampling campaigns were conducted in the pear orchard. Spatial measurements were collected in 16 points in a regular grid. At each sampling point six measurements were taken around the plant, by placing the device at the ground level below the canopy but above the grass between two rows (Fig.3). In the data post-processing phase, the maximum and minimum values of the averages of LAI values for each campaign day were integrated into the model in the place of literature ones.

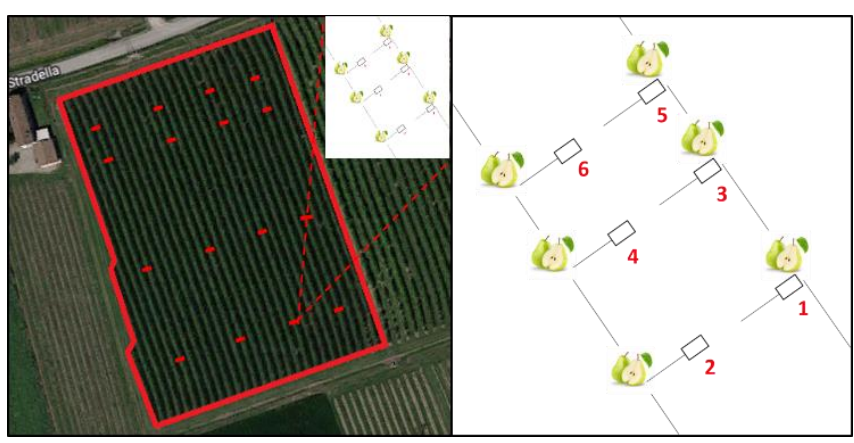

Fig. 3. On the left side the 16 points in a regular grid within the pear orchard. On the right side the sampling design used with AccuPAR LP80 ceptometer.

e) Irrigation scheduling: within the model, irrigations are triggered when soil moisture is below a prescribed threshold to avoid stress for the plant. Additionally, the irrigation depth has been defined as $I=5[\mathrm{~mm}]$ in accordance with the drip-irrigation management system integrated in the experimental site.

f) Simulation period and initial conditions: the simulations have been performed for four consecutive years, from 2016 to 2019. To avoid the effect of the prescribed initial condition, one year of warm up period (2015) has been used and not considered in the analysis. LAI values directly measured at the field collected in the 2019 irrigation season have been used to simulate the modified scenario $\left(\mathrm{S}_{L A I}\right)$ also for the previous years.

\section{RESULTS AND DISCUSSION}

The reference $\mathrm{LAI}_{\mathrm{MAX}}$ value in the model database for the specific plant is $3\left[\mathrm{~m}^{2} \mathrm{~m}^{-2}\right]$. In contrast, averaged measurements obtained based on the field campaigns showed a much lower value, i.e., $\mathrm{LAI}=1.7\left[\mathrm{~m}^{2} \mathrm{~m}^{-2}\right]$. For both cases, there is a $\mathrm{LAI}_{\text {GRASS }}=0.5$ added to consider soil cover (grass) and $\mathrm{LAI}_{\mathrm{MIN}}$ was defined to be equal 0 . The differences are depicted at Fig. 4 for the year 2017, as an example. The results show a similar LAI curve trend, but with the lower growth phase curve of the modified scenario $\left(S_{L A I}\right)$ in comparison to the reference scenario $\left(S_{\text {ref }}\right)$.

Among the different effects of the LAI to the model behavior, we identified the decreasing of the potential transpiration (Fig. 4). Specifically, a similar trend but with a much lower plant water demand is detected in the case of the modified scenario $\left(S_{L A I}\right)$ in comparison to the reference scenario $\left(S_{r e f}\right)$. On average, the differences between the four years have been quantified in a range from 52 to $59 \mathrm{~mm} /$ year, with a standard deviation of $35 \mathrm{~mm}$.

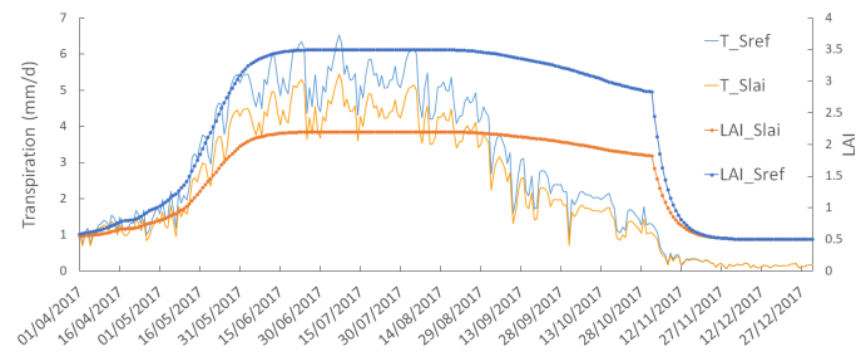

Fig. 4. Time series of the Leaf Area Index $(L A I)$ and potential transpiration $\left(T_{p}\right)$ for both reference $\left(S_{r e f}\right)$ and modified scenario $\left(S_{L A I}\right)$

Figure 5a presents the cumulative precipitation over the simulated period. Noteworthy, there is a strong variability in the meteorological conditions. The year 2017 is characterized by low precipitations, with approximately $500 \mathrm{~mm}$ of cumulative precipitation. In contrast, the year 2019 is the rainiest year, with approximately $900 \mathrm{~mm}$. The year 2016 and 2018 are characterized by similar precipitation amounts $(660$ and $670 \mathrm{~mm}$ respectively). For this reason, despite the relatively short simulation period (4 years), the results obtained and discussed in the present study represent a variety of hydrological conditions and water requirements.

Regarding irrigation, a lower number of events compared to the reference scenario have been quantified, on average 4 events. Consequently, a lower total irrigation water need is also estimated $(19 \mathrm{~mm})$. The results are shown in Fig. 5b,c.

More specifically, in 2016 there was a decrease in water use of $32 \%$, compared to lower $8 \%$ and $15 \%$ for 2017 and 2018, respectively. In contrast, during the year 2019, more irrigation events (and total irrigation) have been simulated with the modified scenario $\left(\mathrm{S}_{L A I}\right)$ then with the reference one $\left(\mathrm{S}_{r e f}\right)$. This result can be explained considering that the year 2019 is a rainy year (see fig.5a). In this condition, irrigation requirements are very low and for this reason the LAI parameter variation had less impact.

Overall, the results confirm the sensitivity of this model output to the LAI values. Therefore, agro-hydrological models should be integrated with accurate values of plant 
parameters to provide a good support system for irrigation and water management. It should be noted, however, that ground-based LAI measurements as collected within the present work can be time consuming, cost-intensive, and spatially and temporally limited. As such, this study supports the use and integration of LAI parameters estimated by optical remote sensing. Specifically, multispectral images collected using a camera installed on a drone can be used to obtain information about vegetation indexes (e.g., NDVI) [7], [21]. Alternatively, satellite remote sensing data are frequently used in this context [22]. Noteworthy, recent Sentinel 2 optical missions provide high spatial and temporal resolution data that can be exploited for agricultural studies [11]. Further studies will be conducted to assess the accuracy of these approaches at the specific field conditions.

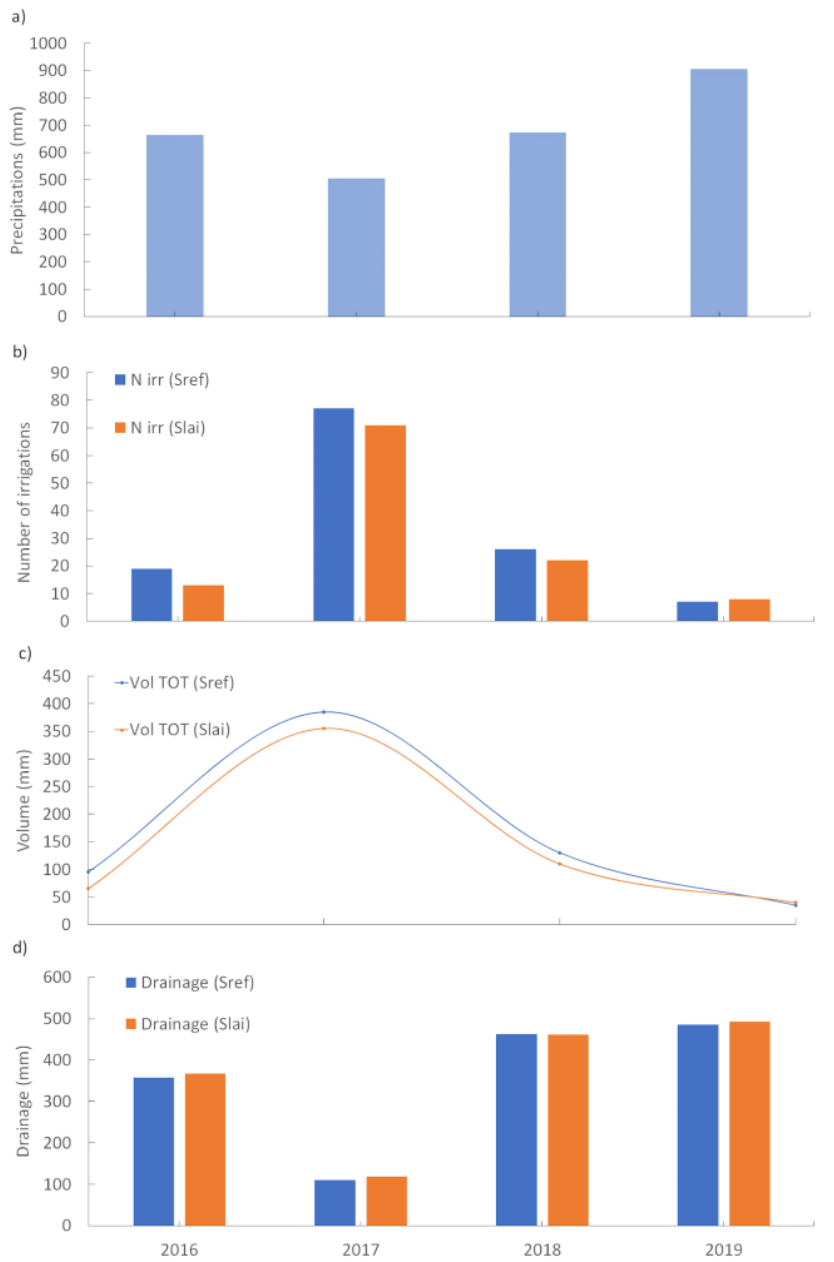

Fig. 5. Cumulative precipitation during the different simulated years (a). Comparison of number of irrigations (b), total irrigation water requirements (c), and deep drainage (d) based on the reference scenario $\left(S_{r e f}\right)$ and the modified scenario $\left(S_{L A I}\right)$

The simulations performed based on the two scenarios are further compared considering the simulated deep drainage. This is defined as the water fluxes through the last layer of the soil root zone and it can be considered as the potential groundwater recharge. For this reason, this estimation can be very relevant for the management of the aquifer and the assessment of sustainable water withdrawal. The results are shown in figure $5 \mathrm{~d}$.

The results show a strong correlation between the deep drainage and the precipitation, as expected. During the driest year (2017) a lower drainage is detected. In contrast, during the rainiest year (2019) a highest drainage is obtained. On average, cumulative water drainage is greater in the modified scenario $\left(\mathrm{S}_{L A I}\right)$ than the reference one $\left(\mathrm{S}_{r e f}\right)$. However, the average difference between the scenarios is $6 \mathrm{~mm}$. Thus, it is important to note that this difference is much lower than the difference detected for the irrigation water requirements (19 mm). For this reason, the results highlight that different input and parameters can be important for improving the model performance depending on the output considered.

\section{CONCLUSIONS}

The agro-hydrological model CRITERIA-1D was assessed to understand its sensitivity to the parameter leaf area index (LAI). Two simulations have been defined, one using literature $\mathrm{LAI}_{\mathrm{MAX}}$ values $\left(\mathrm{S}_{r e f}\right)$, the other using values directly measured at the field site $\left(\mathrm{S}_{L A I}\right)$. From this analysis, it has been shown that the model is very sensitive to the difference that has been determined between database and measured LAI values, when the simulated irrigation water requirement is targeted. Thus, the results confirm the importance to integrate measured LAI values to better estimate irrigation water requirements and to support agricultural water management. Specifically, the study supports the use of remote sensing approaches for detecting vegetation characteristics over large areas and in almost real time that should be integrated into agro-hydrological models. The study has also shown, however, that smaller differences between the two scenarios have been detected when looking at the simulated deep percolation and potential groundwater recharge. For this reason, the importance to integrate measured LAI values is not relevant for further improvements of the model performance when this model output is targeted.

Overall, the results show that sensitivity analyses can be performed to support data collection and model improvements and it highlights the importance of using multi-output for a proper assessment of the agro-hydrological model. This study is part of a broader analysis of the CRITERIA-1D model for estimating irrigation water requirements and supporting agricultural water management. In this contribution, the attention was focused on the parameter LAI principally because of its strong relation with the light distribution and therefore a direct connection with the photosynthetic activity of the plant. CRITERIA-1D estimates LAI values through equation (1), further analyses can be focused also on the evaluation of the parameters sum degree day and the thermal thresholds. Additional analyses are also planned regarding other CRITERIA 1D input like soil parameters, water table depth and weather data. All these scenarios will be compared to the reference case, as it is shown in this study. These results should provide a better understanding of which input is most relevant within the specific model, and they should identify the priorities of data collection and for further model improvements.

\section{ACKNOWLEDGMENT}

This study has been conducted within the SWAMP project. This project has received funding from European Union's Horizon 2020 research and innovation programme under grant agreement No. 777112.

\section{REFERENCES}

[1] G. Rallo, C. Agnese, M. Minacapilli, and G. Provenzano, "Comparison of SWAP and FAO Agro-Hydrological Models to Schedule Irrigation 
of Wine Grapes," J. Irrig. Drain. Eng., vol. 138, no. 7, pp. 581-591, Jul. 2012, doi: 10.1061/(ASCE)IR.1943-4774.0000435.

[2] W. G. M. Bastiaanssen, R. G. Allen, P. Droogers, G. D’Urso, and P. Steduto, "Twenty-five years modeling irrigated and drained soils: State of the art," Agric. Water Manag., vol. 92, no. 3, pp. 111-125, Sep. 2007, doi: 10.1016/j.agwat.2007.05.013.

[3] G. Villani et al., "Soil Water Balance Model CRITERIA-1D in SWAMP Project: Proof of concept," presented at the 23rd Conference of Open Innovation Association (FRUCT), 2018.

[4] G. Baroni, K. Drastig, A. Lichtenfeld, L. Jost, and P. Claas, "Assessment of Irrigation Scheduling Systems in Germany: Survey of the Users and Comparative Study," Irrig. Drain., vol. 68, no. 3, pp. 520-530, Jul. 2019, doi: 10.1002/ird.2337.

[5] J. Xue and L. Ren, "Assessing water productivity in the Hetao Irrigation District in Inner Mongolia by an agro-hydrological model," Irrig. Sci., vol. 35, no. 4, pp. 357-382, Jul. 2017, doi: 10.1007/s00271017-0542-z.

[6] G. Baroni, A. Facchi, C. Gandolfi, B. Ortuani, D. Horeschi, and J. C. van Dam, "Uncertainty in the determination of soil hydraulic parameters and its influence on the performance of two hydrological models of different complexity," Hydrol. Earth Syst. Sci., vol. 14, no. 2, pp. 251-270, Feb. 2010, doi: 10.5194/hess-14-251-2010.

[7] Junxiang Peng, K. Manevski, K. K. Sørensen, R. Larsen, and M. N. Andersen, "Estimation of leaf area index by UAV(drone) and Sentinel2 multispectral imagery," 2019, doi: 10.13140/RG.2.2.17897.65120.

[8] B. Széles et al., "The Added Value of Different Data Types for Calibrating and Testing a Hydrologic Model in a Small Catchment,' Water Resour. Res., vol. 56, no. 10, p. e2019WR026153, 2020, doi: 10.1029/2019WR026153

[9] G. Schoups, J. W. Hopmans, C. A. Young, J. A. Vrugt, and W. W. Wallender, "Multi-criteria optimization of a regional spatiallydistributed subsurface water flow model," J. Hydrol., vol. 311, no. 14, pp. 20-48, Sep. 2005, doi: 10.1016/j.jhydrol.2005.01.001.

[10] G. Nearing, S. Yatheendradas, W. Crow, X. Zhan, J. Liu, and F. Chen "The Efficiency of Data Assimilation," Water Resour. Res., vol. 54, no. 9, pp. 6374-6392, 2018, doi: 10.1029/2017WR020991.

[11] A. Dalla Marta et al., "Integrating Sentinel-2 Imagery with AquaCrop for Dynamic Assessment of Tomato Water Requirements in Southern Italy," Agronomy, vol. 9, no. 7, p. 404, Jul. 2019, doi: 10.3390/agronomy 9070404 .
[12] G. D'Urso, "Current Status and Perspectives for the Estimation of Crop Water Requirements from Earth Observation," Ital. J. Agron., vol. 5, no. 2, p. 107, Jun. 2010, doi: 10.4081/ija.2010.107.

[13] G. Baroni et al., "A comprehensive distributed hydrological modelling inter-comparison to support processes representation and data collection strategies," Water Resour. Res., Jan. 2019, doi: 10.1029/2018WR023941.

[14] T. Francke et al., "What Did Really Improve Our Mesoscale Hydrological Model? A Multidimensional Analysis Based on Real Observations," Water Resour. Res., Nov. 2018, doi: 10.1029/2018WR022813.

[15] R. Sessa, "FOR CLIMATE CHANGE ASSESSMENT, MITIGATION AND ADAPTATION [ GTOS 52 ]," p. 44

[16] P. M. Driessen, "The water balance of the soil," in Modelling of agricultural production: weather, soils and crops, Pudoc, 1986, pp. 76-116.

[17] P. M. Driessen and N. T. Konijn, Land-use systems analysis. Wageningen: Agricultural Univ, 1992.

[18] G. Mcmaster, "Growing degree-days: one equation, two interpretations," Agric. For. Meteorol., vol. 87, no. 4, pp. 291-300, Dec. 1997, doi: 10.1016/S0168-1923(97)00027-0.

[19] G. Antolini, F. Tomei, F. Dottori, V. Marletto, M. Van Soetendael, and M. Bittelli, "CRITERIA Technical Manual." 2016.

[20] F. Tomei, G. Antolini, R. Tomozeiu, V. Pavan, G. Villani, and V. Marletto, "ANALYSIS OF PRECIPITATION IN EMILIAROMAGNA (ITALY) AND IMPACTS OF CLIMATE CHANGE SCENARIOS," p. 10, 2010

[21] R. Raj, S. Suradhaniwar, R. Nandan, A. Jagarlapudi, and J. Walker, "Drone-Based Sensing for Leaf Area Index Estimation of Citrus Canopy," in Proceedings of UASG 2019, vol. 51, K. Jain, K. Khoshelham, X. Zhu, and A. Tiwari, Eds. Cham: Springer International Publishing, 2020, pp. 79-89.

[22] K. Richter, C. Atzberger, F. Vuolo, P. Weihs, and G. D’Urso, "Experimental assessment of the Sentinel-2 band setting for RTMbased LAI retrieval of sugar beet and maize," Can. J. Remote Sens., p. 19,2009 